\title{
Feminidad china y control social: La crónica policial y la construcción discursiva de los inmigrantes chinos
}

\author{
Chinese femininity and social control: The chronicle of Crime and the discursive \\ construction of Chinese immigrants \\ Daisy Chumbimune Saravia \\ Universidad Nacional Mayor de San Marcos \\ Contacto: daisy.chumbimune@unmsm.edu.pe
}

\begin{abstract}
Resumen
Este artículo pretende profundizar en la subalternidad de la inmigración china a partir de la crónica policial. La investigación se basa principalmente en fuentes primarias que incluyen algunos de los periódicos y revistas peruanos más importantes y representativos ( $E$ l Comercio, La Prensa y Variedades). Al demostrar que la pasividad, la cobardía y la debilidad son características notables que determinan la feminidad del inmigrante chino, esta investigación destaca la importancia de los roles de género y su tendencia a perpetuar las desigualdades de poder. El objetivo es demostrar que la crónica policial concibe este sujeto en oposición al sujeto ideal que se pretendió cultivar durante la República Aristocrática (1895-1919), en una época en que la modernidad de la nación era entendida en función de la exclusión de unos y otros.

Palabras clave: Inmigración china, crónica policial, subalternidad, República Aristocrática.
\end{abstract}

\begin{abstract}
This article aims to delve into the subalternity of Chinese immigration from chronicle of crime. The research draws upon mostly primary sources that includes some of the most important and representative Peruvian newspapers and magazines (El Comercio, La Prensa and Variedades ). Through showing that passivity, cowardice and weakness are notable features that determine femininity of chinese inmigrant; this research highlights the importance of gender roles and its tend to perpetuate the power inequalities. The goal is to show that the chronicle of crime conceives this subjet as opposed to the ideal subject that is intended to cultivate during the Aristocratic Republic (1895-1919), at time when modernity of the nation was understood in terms of exclusion from one and another.
\end{abstract}

Keywords: Chinese immigration, chronicle of crime, subalternity, 
Aristocratic Republic.

\section{Los excluidos: la inmigración china en la crónica policial}

En las primeras décadas del siglo XX, en pleno período de la República Aristocrática, la inmigración china era vista como un fenómeno inquietante y preocupante. Ello no era nada nuevo en la historia de las relaciones chinoperuanas; sin embargo, en una época signada por los sueños de modernidad y la consolidación del Estado-nación, la presencia china resultó mucho más incómoda que antes. La sociedad, encabezada por la élite criolla, culpaba a este grupo con la idea de que su barbarie lo hacía completamente extraño al cuerpo de la nación. La presencia de chinos, al igual que otros grupos raciales, interpelaba a los peruanos, mas fueron los primeros años del siglo pasado cuando esta minoría se convirtió en una verdadera amenaza social. Se puede decir así que lo chino pertenecía a la esfera de lo plebeyo: esta era reconocida de manera oficial como integrante de la sociedad e identificada con la barbarie, la incivilización, la antimodernidad.

La literatura y, en general, el ámbito académico — que aspiraba a ser la conciencia reflexiva e ilustrada de la sociedad- se esmeró por plasmar esa subalternidad china. Guiados por la ideología de la élite criolla, los discursos respondieron más a un conflicto entre valores occidentales y orientales que a una referencia verídica, compleja e incluyente de su diversidad. La inmigración asiática asociada a China —una civilización en pleno declive- presentó por entonces los rasgos de la barbarie en un proceso de constante difusión de prejuicios, estereotipos y valores. Pero la otredad oriental vino reforzada además por la ideología peruana de la época, que lejos de ser moderna se afincaba aún en lo colonial, es decir, en un sistema de castas. En esa línea, la subalternidad de la inmigración china superó el hecho de ser una visión orientalista, pues fue además parte de una visión colonial arraigada en el país. Said en su renombrado libro Orientalismo (1990) advierte que esta ideología colonial "presenta una gran coherencia interna y un conjunto muy articulado de relaciones con la cultura 
dominante que la envuelve" (p. 37).

El ámbito periodístico fue uno de los principales instrumentos de construcción de imágenes de identidad y alteridad respecto al "otro" inmigrante chino. La visibilización que de la inmigración china hizo la prensa alimentó con creces su estigmatización social. Para Ludmer (1999), esto funcionó también en el relato de delito1, en tanto este delimitó y marcó fronteras entre la cultura y la no-cultura, vale decir, los límites entre los integrantes de la nación y los excluidos de ella: los marginales (pp. 12-13). No podía ser de otro modo, pues, por su condición inherentemente política, el delito ponía en juego las relaciones de poder entre los dominantes y dominados.

El relato del delito, trasladado a la crónica policial, contribuyó a instalar la percepción de inseguridad en el país y, con ello, atribuyó a la inmigración china una identidad delictiva, peligrosa y abyecta. Este género de la prensa moderna fue el más indicado para exhibir el peligro chino y para desde ahí denunciar la incapacidad de los gobiernos de resolver esto o argumentar la instauración de políticas conservadoras, duras y excluyentes. La inmigración china que era pensada más en función de su raza tuvo todas las de perder. Whipple (2013), quien abordó el concepto de decencia, advierte que en la sociedad peruana esta se entendía desde el punto social y racial (p. 22), de ahí que solo la raza blanca era la beneficiada e inmune a los delitos, en oposición a los otros grupos que eran más proclives a la comisión de delitos y más difíciles de reformar que los sectores blancos. Los grupos raciales como el chino, el negro o el indígena eran considerados una plebe, y, como tal, integraban el panóptico social. En palabras de Rosas (2005), aquellos “eran vistos como los alteradores del orden público; individuos de escasos recursos y, por tanto, proclives al ocio, al robo, a la violencia, a la insubordinación" (p. 124). Por ello, en el campo delictivo, cuando los inmigrantes chinos ejecutaron acciones violentas o causaron algún problema, la situación se tornó por demás conveniente, pues se naturalizó las ideas preconcebidas sobre ellos.

Sin embargo, durante la República Aristocrática "las razas degeneradas" 
ya no fueron consideradas irremediablemente perdidas sino redimibles, pues el racismo biológico fue reemplazado por una propuesta más optimista que enfatizaba la contribución potencial de los indígenas y los mestizos a la creación de una nación moderna. Sin embargo, como bien señala Aguirre en su artículo “Delito, raza y cultura” (2000), ello no fue el caso de los negros o chinos, por lo general, vistos con desinterés dentro del debate de la nación (p. 176). Lo anterior nos lleva comprender que todavía no se renunciaba a la idea de expulsar a los inmigrantes chinos, tal como demuestran las tesis universitarias o demás discursos de aquel entonces. Dar como absolutas e irremediables las deficiencias del chino significó — aparte de encasillarlo en el delito- renunciar al gran propósito de incorporarlo a la civilización. Se impuso el interés por ubicar la raza a través del delito y por subordinar mediante este procedimiento ideológico al chino, incluso aunque en la vida diaria los delitos de estos tuvieran escasa incidencia. La crónica policial fue así un componente clave e importante en la construcción y continuidad de ciertos imaginarios colectivos sobre la criminalidad china. De ahí que interesa especialmente cómo el poder del discurso periodístico, por conservar el statu quo, controló a los inmigrantes chinos transgresores de la norma a través de la creación de imágenes que marcaron y resignificaron a estos sujetos sociales.

En efecto, la crónica policial no solo sirvió para acusar al chino de acciones criminales o sangrientas, sino también para reactualizar su identidad subalterna. Un caso bastante común y que vale la pena mencionar es la atribución de feminidad, pues ya sea víctima o delincuente lo cierto es que se desplegó una constante de representaciones que alimentaron una visión deformada del inmigrante chino como sexo débil y sobre la base de esta se apresuró el tránsito a su estigmatización, condena y exclusión. Sin duda esto contribuyó de manera conveniente a naturalizar las relaciones de poder, pues más allá de que su feminidad explicó su subalternidad, también reveló su subordinación respecto al grupo criollo. Para analizar lo anterior se ha escogido algunas crónicas policiales de los siguientes medios escritos: El Comercio (1905), La Prensa $(1904,1909)$ y 
Variedades (1914); los cuales son representativos porque consignaban a diario secciones dedicadas a lo policial. Se pretende abordar la representación femenina desde la posición de víctima y delincuente.

\section{La construcción de feminidad china en la crónica policial}

Respecto a su posición de víctima, el delito que señaló más la feminidad fue la agresión, en especial, cuando se confrontó al chino con el criollo. Lejos de establecerse una empatía con su padecimiento, se le asignó una alteridad dada por su supuesta feminidad. Un ejemplo es la crónica policial "Hombre terrible" del diario El Comercio. Publicada en 1905, esta refiere la agresión física a un encomendero chino:

Manuel Vélez es de aquellos caracteres rencorosos que no olvidan fácilmente las ofensas que se le hace y que cuando pueden vengarse experimentan una verdadera satisfacción. Vélez tenía cientos pendientes con el chinito Achón y dando rienda suelta a su carácter se estacionó frente al establecimiento del hijo de Confucio y le arrojó cuanta piedra pudo encontrar al alcance de su mano. (El Comercio, 22 de febrero de 1905,3)

El rechazo al delito e incluso la presencia de la instancia policial se difuminan por cuestiones relativas a las identidades antagónicas de los protagonistas: Manuel Vélez y el chinito Achón. Y es que mientras el primero aparece como violento, rencoroso e irascible; el segundo aparece como alguien miedoso, tal como se observa a través de la emisión de chillidos:

A la primera piedra que cayó al establecimiento, el chino Achón chilló como un condenado, armando un gran escándalo, lo que atrajo al guardia de la esquina, que enterado de lo sucedido, capturó al vengativo Vélez y lo remitió a un calabozo de la comisaría. (El Comercio, 22 de febrero de 1905, 3).

El inmigrante chino posee ciertas marcas como la inestabilidad emocional o la sensibilidad desbordada que se suponía inherentes a las mujeres y a los niños. Esta representación femenina no es coincidencia, sino sirve para favorecer la subalternidad del chino, a la vez que justifica, oculta o alivia, el mal 
comportamiento del sujeto nacional. De esta manera, el sujeto nacional, cuya figura modélica es el criollo, es portador de una masculinidad hegemónica que sitúa a las otras masculinidades al margen. La mayor expresión de ello es el ejercicio de la violencia, según se observa en el ataque al encomendero chino y su establecimiento: "le arrojó cuanta piedra pudo encontrar al alcance de su mano". Poco importa que el delincuente Manuel Vélez — según se desprende del titular "Hombre terrible" - sea configurado como un sujeto bastante agresivo, cuya acción y carácter transgreden a la ley. Esto no genera censura alguna e incluso existe una intención soterrada por encontrarle un móvil al delito (un perjuicio anterior que hizo el chino), de manera que se le excluya al chino del proceso de victimización.

La confrontación de femenino/masculino es importante porque perpetúa las relaciones de poder. Zabalza resume bien lo anterior: "Lo pasivofemenino-bárbaro versus lo activo masculino-civilizado entra en juego para 'silenciar' a todos los que estorban al progreso de la nación" (2013, p. 20). Con la feminidad se niega idoneidad física y psíquica al inmigrante chino, de ahí que sea percibida como un escollo que debe ser eliminado por el hombre ideal "verdaderamente viril" e identificado como activo-masculino y trascendente. La lectura del delito se contempla así como el dominio del uno sobre el otro, pero también como la vuelta al orden, la reafirmación de las jerarquías sociales, entre un dominado y un dominante. En continuidad con la ideología hegemónica, más colonial que moderna, la representación femenina de la inmigración china fue resultado de una concepción del delito basada en una serie de discursos preexistentes sobre estos, antes que basada en una transgresión a la ley. En ese sentido, tanto la feminidad como masculinidad fueron construcciones sociales y artificios discursivos (Zabalza, 2013, p. 10) de la época para distinguir a los sujetos y plasmar las relaciones de poder. Ahora bien, la presencia del positivismo en estas configuraciones discursivas es significativa porque la feminidad china no es creación nueva sino forma parte precisamente de la serie de patologías adjudicadas a la raza asiática; tal como se observa en la tesis 
emblemática de Clemente Palma, El porvenir de las razas (1897), el chino en su conjunto "era débil como una tribu infantil, débil como un gigante baldado y decrépito, incapaz de todo esfuerzo, incapaz de toda iniciativa y de toda actividad" (p. 5). Su decrepitud o el ser físicamente débil parece ser el rasgo positivista que sustentó la feminidad2, pues ello se entendió como una desviación sexual y genérica de hombres que viven como mujeres.

La feminidad del chino, según se observa, está definida en cuanto a esencialidad o conjunto estable de atributos que ni siquiera varía en las coyunturas. De hecho, los motines obreros de mayo de $1909^{3}$ durante la República Aristocrática fueron la ocasión propicia para plasmar esto. Un ejemplo es la crónica policial "Los graves sucesos de ayer”, del diario La Prensa. Aquí se destacan los ataques de los obreros y público en general a encomenderías chinas en las calles Capón y Albaquitas:

\footnotetext{
Cierra puertas general.

Las cien y más tiendas que existen en las calles del Capón y Albaquitas se cerraron por encanto y sus moradores dando alaridos casi salvajes escalaban techos y paredes en busca de sitios seguros, pues creían que iban a ser asaltados dentro de sus casas. Estos chillidos de los chinos unidos a los gritos del pueblo y al ruido seco de las piedras al chocar con las puertas y los cristales llevó el pánico a los habitantes de las calles vecinas. (La Prensa, 10 de mayo de 1909, 1; énfasis mío)
}

De manera similar a la crónica policial "Hombre terrible”, una vez más, la víctima es representada con rasgos de feminidad opuestos al nacional, masculino por antonomasia. La referencia a chillidos u "alaridos casi salvajes" es una marca de su inestabilidad emocional o sensibilidad desbordada a través de la cual se enfatiza su pasividad. De esta manera, lo femenino/masculino es el antagonismo que define los roles del sujeto nacional y del chino. Mientras al primero le concierne una masculinidad hegemónica, expresada en la violencia ejercida (arrojar piedras); al segundo le corresponde la feminidad, formulada en la intimidación y no defensa (lanzar gritos). Sin embargo, no existe censura a esa violencia y de hecho los manifestantes obreros son concebidos como los 
decentes, los trabajadores, los masculinos frente a los otros. Ambas crónicas policiales, ocurridas de manera cotidiana y coyuntural respectivamente, evidenciaron que si el delito proviene de la sociedad peruana a la inmigración china, este se debe revertir a través la feminidad de los chinos, pues aquello fuera de lo natural es reprochable.

Así, el discurso de la crónica policial sacó a relucir una línea divisora entre el ideal de hombre — varón, macho, masculino-y los demás sujetos que dejó fuera, entre ellos el inmigrante chino que no alcanzó el perfil propuesto. No hay que olvidar, pues, que los ataques son vistos como parte de las interacciones cotidianas entre dominantes y subordinados, donde se enfatiza la masculinidad y virilidad de uno en desmedro del otro. Lo curioso es que frente al chino, la masculinidad de los otros (mulatos, cholos o negros) estaba garantizada, incluso a pesar de conformar la plebe y no la élite criolla. La apropiación de la tradición popular criolla y la puesta en marcha de su continuidad fue una ventaja de estos frente al inmigrante chino aún reacio a asimilar la cultura criolla. En tal sentido, como bien señala Velázquez (2005), la asignación del género expresó una relación de poder que partió del reconocimiento cultural o mejor dicho de una “apropiación de símbolos culturales ajenos", los cuales le permitieron "legitimar sus modelos de lo 'masculino' y lo 'femenino"”, (p. 60). No obstante, es preciso reparar en que los roles de género asignados no se caracterizan por su permanencia sino por su mutabilidad. Un ejemplo paradigmático lo constituyó la comunidad africana, pues en el caso de los esclavos hombres estos fueron adscritos a lo femenino, "asignándosele atributos que pretendían probar su incapacidad de vivir autónomamente"; aunque de manera simultánea estos mismos fueron provistos de atributos masculinos que hacían temer su pronta sublevación (Velázquez, 2005, p. 66). La necesidad de control social generó esta ambiguiedad, y una réplica clara se daría años después con los inmigrantes chinos.

En efecto, esta representación cercana a la feminidad entró en tensión con la agresividad exhibida, rasgo de virilidad que, de manera particular, apareció 
en su posición no de víctima sino de delincuente. Si en su papel de víctima la feminidad sirvió para mitigar o revertir el delito cometido contra el inmigrante chino, en su rol de delincuente esta se mantuvo, aunque se le agregó la agresividad: un campo de acción dirigido a su mismo grupo o a otros más débiles como los integrados por niños o mujeres. De hecho, la agresión a los menores de edad también tuvo bastante acogida por parte de la prensa. Débil con los hombres pero violento con los niños, el chino se trasfiguró también en el déspota oriental, el bárbaro, el primitivo, el violento apasionado y desenfrenado.

El maltrato o abuso a menores era el interés de muchos cronistas. Los medios escritos reservaron un espacio importante para estos delitos y su asiduidad puede observarse en las crónicas policiales de menor extensión, aquellas que se publicaban de manera diaria y ofrecían la lista de detenidos en la comisaría. Algunos ejemplos son los siguientes: "En la comisaría [...] Alejandro Asan por dar una puñalada al menor Pedro Infantas en la calle Tumbes" (El Comercio, "Sección Callao", 27 de septiembre de 1917, 5); o "En la comisaría han tenido alojamiento gratis las siguientes personas [...] José Ajón, un chinito de catorce años que debe ser descendiente de bóxer por herir en la frente al menor Luis Silla" (La Crónica, 15 de febrero de 1914, 4). El uso exacerbado de la violencia se destaca en la información, incluso a pesar de que —en el último caso- el delincuente tiene catorce años y es un adolescente; sin embargo, ello no lo exime de ser condenado. Todo lo contrario, su agresividad incluso es remarcada al ser comparado con un bóxer ${ }^{5}$.

Las agresiones a los menores por parte de los chinos fueron tema recurrente en los diarios a lo largo de los años. Así, se informó de golpes y puñaladas, pero también de secuestros y asesinatos. Muchas veces no era necesario siquiera las pruebas, sino la simple sospecha para acusar al inmigrante chino, tal como plasma la crónica policial titulada "Secuestrado": "Ha sido detenido en la intendencia de policía, el chino San Ton de quien se sospecha sea el autor del secuestro del menor Carlos Bolívar, desaparecido hace dos días" ( $L a$ 
Crónica, 15 de febrero de 1914, 3). En tal sentido, aunque es verdad que los delitos existieron, también es cierto que la crónica policial aprovechó esta oportunidad para reforzar el imaginario social sobre el chino, en especial, lo referente a su agresividad. Como se recuerda, el inmigrante chino poseía rasgos de femineidad, en el sentido de mostrarse pasivo, débil y quejoso; algo ajeno a la inusitada violencia que adquiere como delincuente y que lo acerca más bien a una masculinidad, eso sí, inferior. En esas tensiones entre lo femenino y lo masculino, el sujeto no puede volcarse sobre lo masculino hegemónico (el criollo) o sobre las otras masculinidades superiores, de ahí que solo pueda actuar sobre los grupos más débiles: los niños y las mujeres. La violencia contra los niños, en ese sentido, permite naturalizar las relaciones de poder establecidas entre superiores e inferiores, sin descuidar la idea de que el chino es peligroso. De hecho, su delito se torna más escandaloso y cuestionable por tratarse de menores de edad.

Un ejemplo es la crónica policial "Celador municipal" publicada en el diario La Prensa en 1904. La denuncia va dirigida al chino, pero sobre todo a la inacción de la autoridad policial. El menor agraviado no sería otro que un expendedor de ese diario y, por esa razón, desde el inicio no se pierde tiempo en denunciar la actitud del celador municipal que vigilaba el mercado: "El de la plaza del mercado cometió una falta grave y usurpó atribuciones" (La Prensa, 28 de octubre de 1904, 6).

En efecto, la acusación contra el celador es calificada de falta grave y de una usurpación atribuida, pues no era policía sino un vigilante. La condena anticipada del celador es el preámbulo para la explicación de lo sucedido, es decir, la agresión al menor:

Un chino por cualquier cosa maltrató a un chiquillo expendedor de $L a$ Prensa, golpeándole en la cabeza con una talega que contenía monedas de cobre, al extremo de hacerle llorar y de causar indignación entre los que presenciaron tan brutal como cobarde acto.

La descripción del maltrato al menor, sin embargo, no deja de lado la construcción de todo un núcleo argumentativo que justifica el rechazo al 
inmigrante chino a través de características adjudicadas a su subalternidad. En principio, se señala que el móvil del delito fue irrelevante: "por cualquier cosa maltrató a un chiquillo"; aspecto que le otorga un rasgo de irracionalidad al chino. Así, los detalles del delito contrastan con una ausencia de explicación sobre el contexto en el que este ocurrió, pues se oculta lo sucedido antes de la agresión. Luego de eso, las referencias al duro golpe propinado (le dio un golpe en la cabeza con una talega llena de monedas de cobre) y las consecutivas lágrimas de la víctima le otorga rasgos de agresividad, por lo que el chino además de impulsivo es violento e incluso insensible. En esa línea, la operación narrativa sobre la retórica utiliza los términos de "brutal" y "cobarde" acto para calificar el delito cometido; alusión que más allá de la violencia ya estipulada pone énfasis en la cobardía. Incluso con la violencia ejercida, una vez más no se desconoce la feminidad del chino, pues si la bravura y el coraje son atributos de masculinidad; la cobardía, ausencia de estos rasgos, se vincula con la feminidad.

Por si fuera poco, la referencia a "causar indignación entre los presentes" apela a la voz de la gente, la cual se sitúa como autoridad de los valores sociales hegemónicos. De esa forma se produce la operación narrativa para la atribución de legitimidad, pues la interpretación emotiva de la gente fortalece la postura de condenar al inmigrante chino. Frente a ello, y como parte final del discurso, se acusa el proceder indiferente de la policía:

La madre del niño eleva su queja al celador municipal y este que debió remitir el hecho a conocimiento de la autoridad de policía, a influencia de otro chino, ordenó que el golpeador siguiera su camino como si tal cosa.

La queja de la madre ante el celador municipal no obtiene buena respuesta, por lo que este es el punto fundamental para que el discurso cuestione las acciones de la institución policial, vale decir, la indiferencia del celador ante el hecho y su supuesta complicidad con los chinos (se dice que por influencia de un chino no se arrestó al acusado). En el discurso esto último resulta interesante, pues, a la par que se convive con la idea de que la inmigración china es lo 
subalterno - por lo que se da una suerte de apelación al imaginario para representarlo y condenarlo—, se cuestiona la legalidad del Estado, su aplicación misma de la justicia. Ludmer, en El cuerpo del delito (1993) da cuenta precisamente de dos legalidades. Para la investigadora, el descrédito de la legalidad supone entonces el triunfo de una segunda legalidad de carácter social —que en verdad es una ilegalidad-que convoca las diferencias económicas, sociales o políticas, además de las diferencias de género y raza (p. 5). La segunda legalidad que habita en el imaginario se superpone como la única verdad y, en función de eso, la atribución de feminidad dentro de la representación subalterna del chino se consolida.

Otra crónica policial similar que cuestiona la actuación policial es "Abuso de un policial", publicada por el diario El Comercio en 1905. Esta refiere la agresión de un encomendero chino a un menor y la información de lo sucedido es recogida de la denuncia. El testimonio del padre del niño, Marcos Espinoza, es presentado en las siguientes líneas:

Anteanoche, á eso de las 11, Espinoza que es de oficio panadero, llegó a su casa situada en la calle San Carlos $N^{\circ} 843$, y supo por denuncia de su mujer que un chino llamado Liao Sang, dueño de una encomendería situada en la misma calle, le había pegado un palo a un hijo suyo de pocos años de edad. (El Comercio, 14 de febrero de 1905, 24; énfasis mío)

El maltrato del inmigrante chino al niño, una vez más, sirve para la distinción de su subalternidad. Y es que si bien se describe la agresión del encomendero Liao Sang de manera breve y concisa: "[el chino] le había pegado un palo a un hijo suyo de pocos años de edad", el discurso no pierde tiempo en proyectar de manera implícita una imagen cruel e insensible de este. La mención a la temprana edad del niño sirve para tal fin, además que se establece a partir de ahí un proceso de victimización, vale decir un lazo de conmiseración y empatía con la víctima. En la sucesión de ello, el cronista sanciona al agresor y se identifica con el malestar del padre de familia, Marcos Espinoza: "Justamente indignado, Espinoza se dirigió a la encomendería de Liao Sang, a quien increpó en su conducta, pero el chino, irascible de suyo, armó una grita infernal" 
Aquí, mientras la mención misma a "justamente indignado" expresa su postura a favor del padre del niño incluso antes de la investigación, la subalternidad del inmigrante chino se refuerza. La operación narrativa sobre la retórica aparece en el discurso y, a través del calificativo "chino irascible", incide en su carácter pasional, mientras a través de los términos "grita infernal" se repara en su feminidad. Así, el chino confrontado con el niño es un sujeto masculino, pero comparado con el criollo es uno femenino. Los gritos son las muestras exageradas que remarcan — como en otras ocasiones- agresividad, pero también cobardía y carencia de virilidad en su carácter. El discurso así dispone la confirmación del imaginario sobre el chino, pues el maltrato físico realizado contra el menor no devela sino los límites de su propia violencia. Y es que si la violencia de Liao Sang contra el niño llega a los golpes, la violencia contra el padre solo se reduce a los gritos. Lo curioso es que, a semejanza de la crónica policial anterior, en esta más allá de la indignación ante el agresor chino existe una indignación mayor ante la autoridad policial.

En efecto, el discurso desde un inicio - recuérdese el título "Abuso de un policial"- se enfoca en sancionar la actitud del policía, pues el inspector que interviene en la trifulca sale en defensa del encomendero chino. El comportamiento del inspector es explicado de la siguiente manera:

[...] esto atrajo al inspector $\mathrm{N}^{\circ} 52$, quien sin enterarse de lo que ocurría ordenó de malas maneras a Espinoza que se retirara y como este pidiera el castigo de Liao Sang, el inspector se sulfuró y enarbolando la vara, descargó rudos golpes. (El Comercio, 14 de febrero de 1905, 24)

Al igual que en la crónica "Celador municipal”, aparece la acusación de complicidad entre el inmigrante chino y la policía. En tal sentido, si bien el diario El Comercio se esmera por construir la subalternidad del asiático a partir de los rasgos femeninos, la censura o reprobación alcanza también a la autoridad policial, según indican las últimas líneas: "Nos parece injusto el proceder de este oficial, por lo que pedimos su rectificación e inmediata destitución de la 
comandancia". Incluso aunque solo se cuente con el testimonio del denunciante Marcos Espinoza, ello es prueba suficiente para dar por cierto el trato adusto del policía, así como la feminidad del chino. Nada se cuestiona ni pone en entredicho si el involucrado es un subalterno como el inmigrante chino.

A diferencia de su posición de víctima, si el delito proviene de la inmigración china a la sociedad, esta misma feminidad aparece y se complementa con rasgos de masculinidad (agresividad) de manera conveniente para no contradecir el peligro que representa. Dicha agresividad tuvo visos de mayor intensidad, pues las crónicas policiales sobre estos maltratos a menores transitaban de la agresión al asesinato. Un ejemplo es la crónica policial "El crimen del Callao", publicada en la revista Variedades en 1915. Esta da cuenta del asesinato del menor Fidel Morán a manos del chino Allón Llun. Las primeras líneas refieren lo siguiente: "Los diarios han dado cuenta ya del crimen cometido por un asiático impulsivo en el Callao, que asesinó a una tierna criatura por fútiles motivos" (Variedades, 6 de diciembre de 1915, 1276).

Desde el inicio, el discurso se esmera por construir identidades polarizadas entre la víctima y el delincuente, incluso antes de exponer los hechos. La operación narrativa del lenguaje, a través de la modalidad argumentativa, busca generar aversión contra el criminal Allón Llun, al mismo tiempo que propicia una emoción y empatía con la víctima Fidel Morán. En el caso de Allón Llun, para suscitar su aversión se construye un núcleo cognitivo adecuado para justificar su subalternidad y alejarlo en ese sentido de la cotidianidad del resto de varones. La operación narrativa sobre la retórica califica al criminal de "asiático impulsivo", en aras de enfatizar su pasionalidad, irracionalidad y violencia. Este rasgo se vuelve a reafirmar con la alusión de "fútiles motivos" de su acción, pues su reacción, en apariencia, no guardó estímulo con lo provocado por la víctima; de ahí que el desequilibrio entre la acción del chino y del niño sea lo que finalmente se condene. En cambio, en el caso de Fidel Morán, para suscitar empatía se realiza el proceso de victimización, 
proceso mediante el cual la víctima es configurada como un símbolo de pureza e inocencia debido a su corta edad. Así, la operación narrativa sobre la retórica lo califica de "tierna criatura”, en una suerte de glorificación póstuma. Según se observa, hasta aquí la crónica no tiene valor informativo, pero sí mucho caudal sensacionalista.

Al igual que los estereotipos del chino, un factor importante es la victimización del niño a través de la edad. La vulnerabilidad social, que apela a los riesgos biológicos e individuales, sirve así para rechazar, separar y aislar al otro chino. Sin embargo, dicho factor que apresura la condena no es del todo completo, pues la distancia de edad entre Fidel Morán y Allón Llun no es tan larga como se presenta; de acuerdo con las fotografías, mientras el primero parece tener entre nueve y doce años, el segundo posiblemente esté entre los doce y catorce años de edad. Sin embargo, para efectos de la crónica policial, lo anterior no parece tener importancia, tal como se aprecia en las infografías que reiteran lo afirmado. Mientras, la fotografía del criminal ${ }^{5}$ dice lo siguiente: "El asiático Llun que por nimios motivos asesinó en el Callao al menor Fidel Moran” (énfasis mío); la infografía de la víctima ${ }^{6}$ dice: "el cadáver de la desgraciada víctima”. La fotografía post mortem es un recurso visual que otorga mayor dramatismo sobre la víctima. Débil e inocente, la víctima es lo antagónico al delincuente: violento, impulsivo y vengativo. Una imagen conveniente en donde lo femenino ya no está situado en el inmigrante chino, al menos en el sentido de su pasividad siempre aludida. A diferencia de los casos anteriores, y tal vez por la gravedad del caso, la masculinidad está superpuesta en el inmigrante chino, aunque valorada de manera negativa. El reproche a su acción así lo demuestra: "El origen: una broma de mataperro; el hecho, un asesinato bárbaro que revela los crueles instintos del asiático homicida".

La operación narrativa sobre la retórica es utilizada aquí para calificar tanto al delito ("un asesinato bárbaro") y al criminal ("los crueles instintos del asiático homicida"). Lo interesante es que los términos "bárbaro" y "crueles 
instintos" dejan en claro que el crimen no responde a la individualidad de Allón Llun, sino a su colectividad, o mejor dicho, al determinismo biológico del grupo racial al que pertenece. La lógica del discurso es que todo chino es un sujeto violento e irracional. El crimen, en tal sentido, se explica por sí solo. Mientras eso sucede, el discurso oculta de forma conveniente la acción violenta de la víctima, siendo apenas mencionada una vez. La referencia "El origen: una broma de mataperro" es importante porque dilucida que, en realidad, el primer agresor fue Fidel Morán; además, especifica que no se trató de una simple broma, dada la gravedad de maltratos que reportaban los chinos a manos de los mataperros. La reiterada mención a los motivos nimios o fútiles del crimen revela la soterrada complicidad del cronista para resignificar la agresión de Fidel Morán, de modo que esta se convierta en algo de menor intensidad y de nula sanción. En otras palabras, conviene ocultar la violencia del sujeto nacional, es decir, su propia masculinidad si lo que se quiere es condenar al inmigrante chino.

La construcción de la subalternidad siempre se realiza de manera binaria: únicamente en el otro chino se concentra lo ilegítimo, aquello que viola las normas y costumbres sociales; mientras que el sujeto nacional —representado en este caso por el niño criollo — se corresponde con los atributos contrarios. Para que no queden dudas al respecto, se consigna la postura condenatoria de la opinión pública: "el hecho ha presentado viva indignación en el puerto". La operación narrativa de atribución de legitimidad recurre, como en el caso anterior, a la voz de la gente quienes, como autoridad, elevan la sanción. Ello, sin duda, fortalece la subalternidad del inmigrante chino, aunque — según se dijo antes— queda excluida de esta la feminidad. La fiereza del delito que termina en homicidio hace que las ambiguiedades entre lo femenino y lo masculino se disuelvan y que este sea configurado de manera conveniente solo como lo último.

Por todo lo expuesto se puede decir que la representación femenina del inmigrante chino en la crónica policial demuestra cómo la identidad femenina y 
masculina fue utilizada para reafirmar las relaciones de poder entre un dominando y un dominante al interior de la República Aristocrática. En su posición de víctima o delincuente chino, el género se acomodó a conveniencias de la propia intencionalidad ideológica del grupo criollo hegemónico, de modo tal que si el chino fue risible y criticable cuando era mostrado como sujeto femenino, pasivo e incapaz de defenderse; este mismo fue criticable cuando fue un sujeto activo, agresivo y desafiante con los niños. El discurso de la crónica policial no mostró ninguna contradicción en su articulación de lo femenino, y en el contexto delictivo el inmigrante chino siempre resultó un subalterno frente a la sociedad, contrapuesto al sujeto nacional. El discurso de la crónica policial mostró preferencia por lo criollo, y en ese sentido, los hechos delictivos no fueron garantía de verdad, sino solo formaron parte de la estrategia de representación que dispuso este discurso y que ocultó que el carácter del relato fue arbitrario. Todo ello en línea con la ideología hegemónica, que más que moderna era colonial y pensada aún en un sistema de castas. Dentro de este, la esfera de lo plebeyo -integrada por los grupos raciales indígena, negro y asiático-, si bien era reconocida de manera oficial como integrante de la sociedad, en el fondo mantenía su identificación con la barbarie, la incivilización y la antimodernidad no solo por sus rasgos biológicos, sino además por los distintos valores sociales y culturales.

Resulta posible afirmar entonces que, a partir de la representación femenina del inmigrante chino, la crónica policial plasma una identidad subalterna devenida del ejercicio de una legalidad alterna de carácter social, connotativo de una ideología colonial que perdura anacrónicamente dentro del proyecto modernizador de la República Aristocrática. Por tanto, se sostiene que el discurso de la crónica policial conformaría una aplicación jurídica alterna o una sanción textual-temporal independiente del Estado, por la misma desconfianza o descreencia ideológica en la modernidad y sus elementos de justicia. 


\section{Notas}

${ }^{1}$ Josefina Ludmer en El cuerpo del delito (1999) realiza un recorrido por la literatura argentina con el fin de indagar en las particularidades del relato sobre el delito. Su premisa es que el delito es un artefacto histórico que sirve para delimitar la historia e identidad nacional, pues circunscribe las pertenencias y exclusiones. En tal sentido, el delito es un instrumento que organiza también la historia literaria del siglo XX.

${ }^{2}$ La feminidad es parte de la degeneración asiática. No obstante Salessi, en su libro Médicos, maleantes y maricas (1995), señala que si bien la desviación sexual era una marca marginal esta podía ser tolerada dentro de las clases altas. El miedo más bien se orienta a las clases obreras, burguesas y también a los inmigrantes extranjeros: rostros masculinos nuevos. La construcción de la inversión sexual o feminidad se dirige a ellos para contrarrestar este miedo.

${ }^{3}$ La inestabilidad económica durante los primeros años del período encontró culpables en la presencia asiática, pues diversos factores como la reactivación de la inmigración china, los reducidos salarios que estos percibían y la paulatina monopolización del comercio urbano y la industria china, confirmaron su posicionamiento laboral. Así, a ojos de los obreros, la llegada de más inmigrantes chinos debía ser impedida. Dicho sector, cada vez más marginado y desplazado, no encontró sino en el chino el motivo de sus pesares. Algo que se observó en las protestas del 9, 17 y 29 de mayo de 1909, donde con el respaldo de la prensa - sobre todo de los diarios anarquistas y sindicalistas— se llegó a grandes niveles de violencia, siendo agredidos los chinos y saqueadas sus encomenderías.

${ }^{4}$ En su estudio sobre la inmigración africana y su presencia en la sociedad peruana, Marcel Velázquez (2005) da cuenta de la necesidad que tuvieron los esclavos africanos para apropiarse de los símbolos culturales de sus amos y también de la plebe. Y es que solo de esta manera podían legitimar sus modelos de género masculino y femenino. Como se ha venido afirmando, la asignación del género expresó una relación de poder y partió del reconocimiento cultural. Ello se fue formando desde hacía mucho tiempo y como tal se trasladó al período de la República Aristocrática.

${ }^{5}$ La coyuntura política de China, en particular la rebelión bóxer (1900-1901), es traída así a colación para resaltar el carácter violento y xenofóbico de los chinos. Y es que esta rebelión surgió contra la influencia de Occidente en el comercio, la política, la religión y la tecnología; por esta razón causó la muerte de cerca de 230 extranjeros y miles de chinos cristianos.

${ }^{6}$ La infografía corresponde a una fotografía en primer plano del asesino Allón Llun con su uniforme de colegio.

\section{Referencias bibliográficas}

Aguirre, C. (2000). Delito, raza y cultura: el desarrollo de la criminología en el Perú. Diálogos en Historia (2), pp. 179-206.

Ludmer, J. (1993). El delito: Ficciones de exclusión y sueños de justicia. Revista de Crítica Literaria Latinoamericana (36), pp. 5-53.

Ludmer, J. (1999). El cuerpo del delito. Un manual. Buenos Aires: Perfil.

Nouzellies, G. (2000). Ficciones somáticas: Naturalismo, nacionalismo y políticas médicas del cuerpo (Argentina 1880-1910). Rosario: Beatriz Viterbo Editor. 
Palma, C. (1897). El porvenir de las razas en el Perú. Lima: Imprenta Torres Aguirre.

Rosas, C. (2005). El miedo en el Perú: siglos XVI al XX. Lima: Pontificia Universidad Católica del Perú.

Said, E. (1990). Orientalismo. Madrid: Editorial Libertarias.

Salessi, J. (1995). Médicos, maleantes y maricas. Higiene, criminología y homosexualidad en la construcción de la Nación Argentina (Buenos Aires: 1871-914). Rosario: Beatriz Viterbo.

Whipple, P. (2013). La gente decente de Lima y su resistencia al nuevo orden republicano. Jerarquías sociales, prensa y sistema judicial en el siglo XIX. Lima: Instituto de Estudios Peruanos, Centro de Investigaciones Diego Barro Arana.

Zabalza, M. (2013). La representación de la feminidad y de la masculinidad en el Facundo. Ontario: The University of Guelph.

Velázquez, M. (2005). Las máscaras de la representación. El sujeto esclavista y las rutas del racismo en el Perú (1775-1895). Lima: Universidad Nacional Mayor de San Marcos, Banco Central de Reserva del Perú. 